\title{
Influence of organic farming practices on selenium concentration of tank milk - a farm study
}

\author{
E. Kuusela ${ }^{1}$ and L. Okker \\ University of Joensuu, Faculty of Biosciences \\ P.O. Box 111, FI-80101 Joensuu, Finland
}

\begin{abstract}
The objective of this study was to determine whether current organic dairy farming practices provide adequate selenium (Se) supply for animals and consumers. The project was carried out as a survey in Eastern Finland. Tank milk samples from 65 farms were analysed at MTT Agrifood Research Finland. The average daily Se supplementation was $4.7 \mathrm{mg} \mathrm{Se} / \mathrm{cow}$. Tank milk Se concentration averaged $0.013 \mathrm{mg} / \mathrm{kg}$. Farms practicing organic animal production resulted in $1 / 3$ lower milk Se than farms practicing only organic crop production $(\mathrm{P}<0.001)$. This study showed that, despite of recommended Se supplementation level, organic farming could not transform it into milk Se concentration.
\end{abstract}

KEY WORDS: selenium, milk, organic farming

\section{INTRODUCTION}

Selenium (Se) is an essential trace element in animal nutrition. The recommended Se content in ruminant diets varies between 0.1-0.3 mg Se $/ \mathrm{kg}$ dry matter (DM) and deficiency symptoms have been observed with 0.02-0.04 mg Se/kg DM and overdoses above $5 \mathrm{mg} \mathrm{Se} / \mathrm{kg}$ DM (Ammerman and Miller, 1975; Russell, 1988; Dhillon and Dhillon, 1999). Because Finnish bedrock and soils are very low in Se, selinite has been added to animal mineral feeds since 1969 and selenate to composite fertilizers since 1984. Today conventional Finnish milk contains approximately $0.030 \mathrm{mg} \mathrm{Se} / \mathrm{kg}$, providing an important human Se source (Eurola et al., 2003). Organic farming does not use mineral fertilizers. Besides extremely low Se content of home grown feeds, organic farming, relying on legume-containing calcium-rich basic fodder, is bound to result in diets of

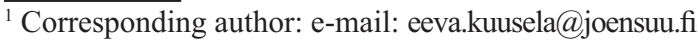


low Se utilization (Smith et al., 1997). Selenite containing supplements, which are permitted in organic farming, are known to increase milk Se concentration less effectively than organic plant Se, which is the normal form of Se intake for cows. Sodium selenite is used in mineral feed supplements and in Se medication, whereas plants and Se yeast contain mainly organic selenomethiene (Ortman and Pehrson, 1999). Selenite may act as a prooxidant, which is potentially toxic at high dietary level, whereas selenomethiene does not possess these properties. The permitted Se content has been increased recently to $0.5 \mathrm{mg} / \mathrm{kg}$ on $880 \mathrm{~g} / \mathrm{kg} \mathrm{DM}$ basis (EC Directive 70/524 for complete feeding stuffs). The aim of this study was to determine whether current organic farming practices can provide adequate $\mathrm{Se}$ supply for animals and consumers.

\section{MATERIAL AND METHODS}

This study was conducted in Eastern Finland in cooperation with the local ProAgria rural advisor centre. During turn of year 2005-2006 tank milk samples (one per farm) were collected from 65 organic dairy farms and analysed for Se at MTT Agrifood Research Finland. Out of 65 farms, 22 were certified for both organic crop and animal production (ORGA) and 43 were practising only organic crop production (ORGF). The number of cows and average annual (2005) milk yield were recorded. Farmers were asked for how long major fodder fields been without mineral fertilization (one year, two years or three or more years).

Farmers were also interviewed for current feeding practices and other Se supplementation. The average daily Se supplementation in supplemental feed was calculated from weekly given doses of purchased feeds and their recorded Se concentration. The average daily Se supplementation in oral Se medication was estimated on monthly basis since the normal practice was to give short intensive courses. Three farms that gave Se injections were excluded from further calculations, because the average daily Se supplementation could not be estimated.

The relation between tank milk Se concentration, number of years without mineral fertilization, and amount of Se supplementation was analysed using Pearson correlation. The effect of practising or not practising certified organic animal production was compared using independent sample t-test.

\section{RESULTS}

The tank milk Se concentration for all 65 farms averaged 0.013 (range 0.005$0.030) \mathrm{mg} / \mathrm{kg}$, which is similar to that for the 62 farms studied further. The average number of cows and milk production per cow for ORGA and ORGF farms were 
28 cows with $7350 \mathrm{~kg}$ milk/cow and 22 cows with $8868 \mathrm{~kg}$ milk/cow, respectively. Tank milk Se concentration increased with increasing Se supplementation $(0.436$; $\mathrm{P}<0.001$ ) with relation to the conversion phase (Figure 1). The longer fodder fields had been without mineral fertilization, the lower was the milk Se concentration $(-0.623 ; \mathrm{P}<0.001)$. ORGA farms had $1 / 3$ lower milk Se concentrations than the ORGF farms $(\mathrm{P}<0.001)$. All farms gave some Se-containing supplementary feeds, $78 \%$ of farms used Se-containing mineral feeds, $25 \%$ Se-containing vitamin feeds, $17 \%$ oral Se medication. The average daily Se supplementation in the form of supplementary feeds and oral Se medication was 4.6 and $0.1 \mathrm{mg} \mathrm{Se} / \mathrm{cow}$, respectively. ORGA farms gave $42 \%$ less supplementary Se than ORGF farms $(\mathrm{P}<0.001)$.

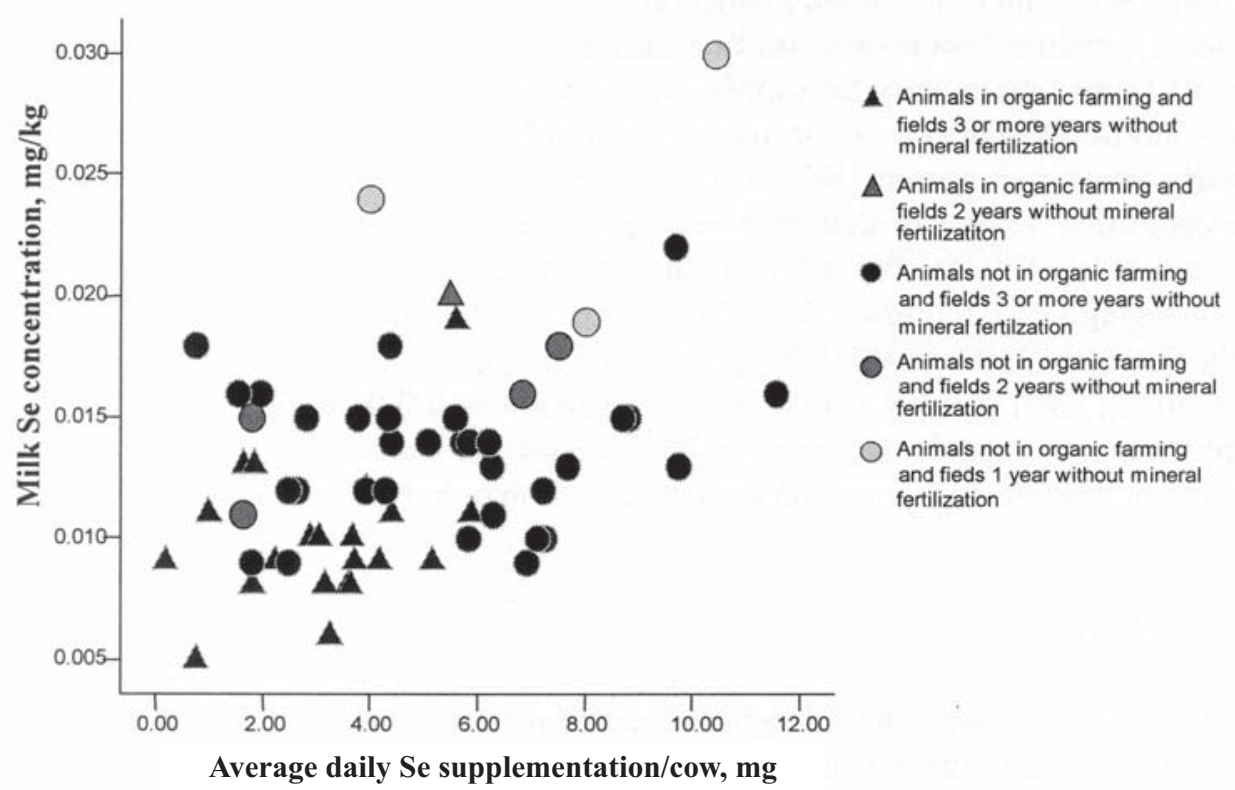

Figure 1. The effect of Se supplementation on tank milk. Se concentration on different farms

\section{DISCUSSION}

Milk Se concentration is an easily measured indicator of Se intake and animal Se status, especially in situations of Se deficiency (Grace et al., 1997). Milk Se concentrations have been reviewed to vary according feeding and management systems from 0.002 to $0.060 \mathrm{mg} / \mathrm{L}$ (Knowles et al., 2006). Milk Se concentration affects human Se supply, especially for children. An early study of Aspila (1991) proposed that desirable milk Se content would be around $0.020 \mathrm{mg} / \mathrm{L}$. However, 
it can still be argued how high milk Se concentration should be and how high doses of different Se forms can be given safely. Should milk satisfy the major Se requirement of consumers or should it satisfy the Se requirement of calves fed with the milk? What is an adequate level for dams?

In the present study, the average milk Se concentration was of similar to that found in a study on organic farms in Sweden, but clearly lower than found in Finnish and Swedish conventional farming (Toledo et al., 2002; Eurola et al., 2003). The efficiency of additive Se supplementation varied between farms probably due to the different proportion of conversion-phase feeds, form of Se in purchased feeds, variation in animals and diets, interval from Se medication and inexact estimations of supplementation. In ORGF farms Se supplementation probably included more organic Se (conventional feeds) than in ORGA farms. On all farms where daily Se supplementation was under $5 \mathrm{mg} / \mathrm{cow}$, the farmers were advised to consider their animal Se supply. However, even the farms that clearly exceeded current Se recommendations, could not obtain a milk Se concentration similar to that obtained by conventional farms. In a recent study Givens et al. (2004) showed that an extreme selenite supplementation level $(1.14 \mathrm{mg} / \mathrm{kg} \mathrm{DM})$, requiring daily Se doses of nearly $20 \mathrm{mg}$, barely increased the milk Se concentration to $0.020 \mathrm{mg} / \mathrm{kg}$, but a permitted level of organic Se yeast $(0.4 \mathrm{mg} / \mathrm{kg} \mathrm{DM})$ yielded a milk Se concentration of $0.028 \mathrm{mg} / \mathrm{kg}$. Some kind of supplementary organic Se seems to be necessary in Finnish organic farming, if aiming at milk Se concentration similar to that on conventional farming.

\section{CONCLUSIONS}

This study showed that, despite of recommended Se supplementation level, Finnish organic farming could not reach a milk Se concentration similar to that in conventional farming. This warrants new approaches.

\section{REFERENCES}

Ammerman C.B., Miller S.M., 1975. Selenium in ruminant nutrition: A review. J. Dairy Sci. 58, $1561-1577$

Aspila P., 1991. Metabolism of selenite, selenomethionine and feed-incorporated selenium in lactating goats and dairy cows. Academic Dissertation. J. Agr. Sci. Finland 63, 1-74

Dhillon K.S., Dhillon S.K., 1999. Adsorption-desorption reactions of selenium in some soils of India. Geoderma 93, 19-31

Eurola M., Alfhan G., Aro A., Ekholm P., Hietaniemi V., Rainio H., Rankanen R., Venäläinen E.-R., 2003. Results of Finnish selenium monitoring program 2000-2001. MTT Agrifood Research Finland, Jokioinen. Agrifood Research Reports 36, p. 42 
Givens D.I., Allison A., Cottrill B., Blake J.S., 2004. Enhancing the selenium content of bovine milk through alteration of the form and concentration of selenium in the diet of the dairy cow. J. Sci. Food Agr. 84, 811-817

Grace N.D., Lee J., Mills R.A., Death A.F., 1997. Influence of Se status on milk Se concentrations in dairy cows. N .Z. J. Agr. Res. 40, 171-172

Knowles S.O., Gace N.D., Knight T.W., McNabb W.C., Lee J., 2006. Reasons and means for manipulating the micronutrient composition of milk from graizing dairy cattle. Anim. Feed Sci. Tech. 131, 154-167

Ortman K., Pehrson B., 1999. Effect of selenate as a feed supplement to dairy cows in comparison to selenite and selenium yeast. J. Anim. Sci. 77, 3365-3370

Russell E.W., 1988. Russell's Soil Condition and Plant Growth. $11^{\text {h }}$ Edition. A. Wild (Editor). Bath Press, Avon (UK), pp. 991

Smith K.L., Hogan J.S., Weiss W.P., 1997. Dietary vitamin E and selenium affect mastisis and milk quality. J. Anim. Sci. 75, 1659-1665

Toledo P., Andren A., Björck L., 2002. Composition of raw milk from sustainable production systems. Int. Dairy J. 12, 75-80 